\title{
NORFACE
}

MIGRATION

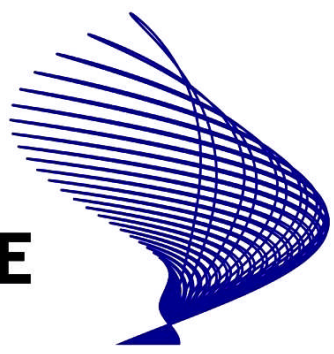

NORFACE MIGRATION Discussion Paper No. 2012-03

\section{Childhood and Family Experiences and the Social Integration of Young Migrants}

Olof Åslund, Anders Böhlmark and Oskar Nordström Skans 


\title{
Childhood and Family Experiences and the Social Integration of Young Migrants*
}

\author{
by \\ Olof Åslund $^{\mathrm{A}}$, Anders Böhlmark ${ }^{\mathrm{B}}$ and Oskar Nordström Skans ${ }^{\mathrm{C}}$
}

December 30, 2011

\begin{abstract}
We use sibling variation in age at migration to study how early life exposure to the host country affects social integration in adulthood. Building on a Swedish population-wide dataset, we show that early experiences affect the probability of living close to, working with, and marrying other immigrants. Segregation also decreases with parental time in the host country before the subject's birth. The effects are permanent and do not arise through differences in education or economic outcomes. Several results instead suggest that social integration is heavily affected by preferences or cultural identities that are set during early, formative, years.
\end{abstract}

Keywords: Immigration, integration, childhood experiences, age at migration, siblings JEL-codes: J12, J15, J13, J01

\footnotetext{
${ }^{*}$ We are grateful for comments from Roger Andersson, Anders Björklund, Per-Anders Edin, Robert Eriksson, Jens Rydgren, participants at the 2007 FAS/SULCIS integration workshop (Stockholm), the 2009 CReAM/Metropolis British Columbia workshop on the economics of immigration (Vancouver) and seminar participants at IFAU, IBF, and SOFI. Preliminary versions of this manuscript were circulated under the title "Age at migration and social integration". The order of the authors is according to the English alphabet and not related to contribution. The research is partly funded by the Swedish Council for Working Life and Social Research (FAS). Böhlmark also thanks NORFACE (MI3) and SUNSTRAT for financial support.

A Institute for labor market policy evaluation (IFAU), CReAM, IZA and Uppsala University, olof.aslund@ifau.uu.se

${ }^{B}$ Institute for social research (SOFI) and CReAM, anders.bohlmark@sofi.su.se.

C IFAU, IZA and UCLS, oskar.nordstrom_skans@ifau.uu.se
} 


\section{Introduction and review of previous literature}

The economic and social integration of childhood migrants and children of immigrants is receiving increasing political attention as many advanced countries experience rapid changes in the demographic composition, alongside a growing fear that socioeconomic disparities between ethnic groups may persist over generations. ${ }^{1}$ It is an apparent fact that people of different descent are separated from each other in everyday life; the neighbors, coworkers, and spouses of immigrants are disproportionally often also immigrants (Zhou 1997, Waldinger and Feliciano 2004, Åslund and Skans 2010). ${ }^{2}$ The individual level determinants of this apparent lack of integration among immigrants are less well understood, despite the phenomenon's potential importance in shaping the structure of future societies.

This paper aims to further our understanding of the social integration process among youths with an immigration background. We study Sweden, where the ethnic composition of the population has changed radically during the past decades. Beginning with labor migrants in the 1950s and 1960s, followed by refugee and reunification migrants from the 1970s, immigration has raised the fraction of foreign-born to 15 percent in 2010, a high figure by international comparisons. The average level of education among immigrants, and children of immigrants, is similar to that of natives with native parents. Yet, labor market performance is poorer among natives with foreign-born parents than among other natives, and a lot poorer among the foreign-born (Rooth and Ekberg 2003). The labor market differentials are substantial also in an international comparison (OECD 2009). In addition, segregation along ethnic lines is prevalent in many different parts of society such as the residential market, the labor market, and the marriage market (see Skans and Åslund 2009).

In particular, we focus on how experiences of the host country in early life influence social integration in adulthood. We also analyze how time spent in the host country by the parents influence the process of social integration. Empirically, we utilize sibling variation in age at migration as a tool to isolate the effects of childhood environments on social integration among individuals with an otherwise comparable background. As our outcomes we take measures of social integration based on the characteristics of the individual's surrounding peers at the residential market, at the labor market, and at the marriage market. We study

\footnotetext{
${ }^{1}$ Both children of immigrants and childhood migrants who are raised and educated in the host country are disadvantaged in terms of economic outcomes compared to children of natives (OECD 2009, Algan et al. 2010).Proposed explanations to these differentials include language skills and other qualifications (Bleakley and Chin 2008, 2010; Portes and Fernandez-Kelly 2008; Nordin and Rooth 2009), but also ethnic discrimination (Carlsson 2009).

${ }^{2}$ Race/ethnicity/origin is indeed not the only dimension along which societies are segregated (see DiPrete et al 2011 for recent evidence), but certainly one where segregation is very pronounced (McPherson et al 2001).
} 
childhood migrants arriving at different ages, but also consider parental time in the host country before the birth of the children, and are therefore able to quantify the extent to which integration of youths is affected by parental time in the host country. The analysis builds on a unique Swedish longitudinal population-wide register data set allowing us to link all individuals not only to their parents and siblings, but also to their neighbors, coworkers, and spouses.

Our methods are designed to handle the potential for reversed causality and omitted variables caused by the fact that the timing of migration and return migration patterns among parents may be affected by many different factors, including the age of the children in the family. By comparing siblings who arrive at different ages, or whose parents have stayed different number of years in the host country before giving birth, we are able to remove many different potential confounding factors such as endogenous time of migration, endogenous return migration, and potential errors in measured time of arrival and thereby isolate the effects of age at migration.

We aim not only to study whether different childhood/family experiences result in different living situations at adulthood, but also to shed light on why this is so. A fundamental distinction is the one between differences in contact opportunities and the desire/tendency to interact with people similar to oneself in a given setting. We argue below that our approach controls for several factors determining contact opportunities, and our analysis of intermediate mechanisms potentially affecting these opportunities suggests that our main results are likely to be driven by the latter explanation. ${ }^{3}$ The literature reviewed below suggests a number of reasons for why age at migration may be important for the future social integration of immigrant youths for reasons other than contact opportunities. We can, for ease of exposition, broadly label these as skill-based or preference-based. An individual's accumulation of skills (human capital, education, languages) can be affected by childhood and family experiences. These skills can also be important for the social integration later in life by affecting economic performance and thereby changing the available opportunities on different markets. Empirically, age at migration is clearly related to labor market outcomes such as employment and earnings (see Schaafsma and Sweetman 2001, Böhlmark 2009, and results presented in Appendix C). Given that early qualifications have been shown to transmit into future performance (Cunha and Heckman 2007), it is not surprising that school performance and

\footnotetext{
${ }^{3}$ The literature labels these basic phenomena in many ways. McPherson and Smith-Lovin (1987) distinguish between induced homophily and choice homophily (see also the discussion in Kossinets and Watts (2009)). McPherson et al (2001) use the terms "baseline homophily" and "inbreeding homophily" and provide examples of other uses.
} 
educational attainment are related to the age at arrival (Gonzalez 2003, Cortes 2006, van Ours and Veenman 2006). However, there is also evidence that the long-term educational impact may be smaller than the short-term effects (Böhlmark 2008, 2009). ${ }^{4}$

Proficiency in the host country language may also have a direct impact on the patterns of social interactions by making it easier to communicate with natives, whereas proficiency in the mother tongue can be equally important for interactions with other immigrants from the same source country. Language complementarities between individuals can lead to efficiency gains in certain parts of the labor market (Lazear, 1999), make living in an ethnically close environment easier, or increase the individual's possibility of attracting a partner of a certain descent. Bleakley and Chin $(2008,2010)$ argue that since the association between age at arrival and educational and economic outcomes primarily appears for migrants to the US from non-Anglophone countries, it is likely that language skills are important for the effects on economic outcomes. They find that English proficiency at adulthood declines with age at arrival for immigrants arriving after age 9, which is consistent with theories of critical periods in learning acquisition. However, they also find that residential segregation is equally affected by age at arrival regardless of home language, thus suggesting that integration, at least partially, may be driven by other processes than those that affect language acquisition.

Many studies suggest that childhood environment and experiences have a strong impact on preferences or cultural identity. Although migrants often express strong ties to both their host country and their source country (Casey and Dustmann 2010, Nekby and Rödin 2010), ${ }^{5}$ it is also evident that experiences (as a child or by the parents) from the two countries may affect the relative strengths of these ties. According to ethnic identity development theories (Erikson 1968), ethnic awareness should increase with age during childhood and adolescence. ${ }^{6}$ Some studies suggest that the process starts very early, and that children have developed an ethnic identity already as three-year-olds (Weiland and Coughlin 1979). ${ }^{7}$

In this paper we also measure the impact of parents' exposure to the host country before childbirth. We address this issue since previous evidence suggests that parents matter for the choices and outcomes of their children in many dimensions. Parental attitudes influence labor market outcomes (Thornton, et al 1983, Fernandez et al 2004), and are likely to be highly

\footnotetext{
${ }^{4}$ See Kao and Tienda (1995), Riphahn (2001), and Chiswick and DebBurman (2004) for further results.

${ }^{5}$ The issue of "oppositional cultures" rejecting the goal of upward social mobility has received particular interest (see e.g. Fordham and Ogbu 1986, Austen-Smith and Fryer 2005, Bisin et al 2006 and Fryer and Torelli 2005).

${ }^{6}$ See Marks et al. (2007) for a review of the empirical support.

${ }^{7}$ We also note that there seems to be mixed evidence on the empirical association between identity and economic outcomes (Clark and Drinkwater 2007, Nekby et al. 2009, Casey and Dustmann 2010, Battu and Zenou 2010).
} 
influential in choices of partners since marriages may serve purposes not directly captured by individual utility; e.g. preserving a group’s cultural characteristics (Kalmijn 1998; Bisin and Verdier 2000). There also seems to be a high degree of intergenerational correlation in identity (Casey and Dustmann 2010). ${ }^{8}$

Our key interest in parental influence is however whether its nature changes with time in the host country. It is easy to see that the capability of assisting with school work is higher when the parent knows the host country language better. Labor market attachment gets stronger with time, which changes the conditions for the offspring, e.g. since larger networks makes non-ethnic workplaces more accessible as entry jobs. But it is also possible that parental attitudes towards life in a native dense neighborhood or towards choosing a native partner may change over time. Previous studies have shown that women more than men tend to be considered as “carriers of culture” (e.g. Warikoo 2005), which suggests that we should expect a greater parental impact for females on outcomes that are tied to family and culture rather than to the labor market if attitudes are more important in the former context. ${ }^{9}$

The insights from the previous literature guide our empirical analysis in four important dimensions. ${ }^{10}$ First, separating out the role played by economic and educational performance is crucial for understanding the underlying process. Second, parental time in the host country may play an independent role for the integration of the children, and the model should account for this. Third, it is important to use a flexible specification between age at arrival and the outcome variable since some processes are expected to be more influential during critical periods (since e.g. language acquisition has been found to be unaffected by time-of-arrival before school-starting age). Fourth, heterogeneous effects by gender, origin, and market may be indicative of how important different potential underlying mechanisms are.

We study individuals born in 1960-1971 who either immigrated to Sweden before age 15 or whose parents arrived in Sweden 10 years or less before the subject was born. Although the time period covers some initial cohorts of refugees and family reunification migrants from fairly distant countries, it precedes the large waves of refugees in the late 1980s and 1990s for

\footnotetext{
${ }^{8}$ Theoretical work studying the mechanisms behind cultural transmission across generations include Bisin and Verdier (2001), and Saez-Marti and Sjögren (2008) who analyze how this interacts with other influences on identity formation.

${ }^{9}$ There is also evidence that country of origin and parental education may matter for the impact of age at arrival; van den Berg et al. (2009), e.g., find such differences in their sibling analysis of height.

${ }^{10}$ We refer to Åslund et al. (2009) for a discussion on immigrant labor market assimilation and to a further discussion on ethnic segregation and its relation to economic integration. See e.g. Borjas (1999) and Lubotsky (2007) for studies of earnings assimilation, and Tezic (2004) for Swedish evidence. A description of residential segregation is provided by Iceland et al (2002), whereas Hellerstein and Neumark (2008) discuss workplace segregation, and Qian and Lichter (2001) and Kalmijn (1998) show evidence on intermarriage and homogamy. Corresponding Swedish evidence can be found in Bråmå (2006), Åslund and Skans (2010) and Dribe and Lundh (2008).
} 
which economic integration has proven particularly problematic. The period we study is instead one of substantial labor migration, often from neighboring countries, and the adult migrants of the time are typically considered successful in terms of economic assimilation, at least when compared to later cohorts.

Despite the relatively favorable economic outcomes among the parents, we document strong segregating patterns among their children. Our analysis shows that childhood exposure to the host country matters in this respect; there is a strong impact of age at migration on integration in adulthood. Arriving five years later increases the fraction of immigrants at the workplace as well as in the neighborhood by about 2 percentage points. The probability of having an immigrant spouse is increased by as much as 12 percentage points. In contrast, we only find small and mostly insignificant effects of being the first-born child of the familyarriving a single year later has a substantially larger impact on integration than being the firstborn child. Parental time in the host country before the subject's birth also has a significant and qualitatively similar impact, although smaller in magnitude. This suggests that the effects on integration partly work through own experiences and partly through parental experiences.

Further results show that the findings are unlikely to be explained by differences in educational and economic outcomes among the children or the parents. Instead, several observations point to the importance of early influences on ethnic identity and social ties to the country of origin. Although the effects are present for all immigrant groups (including those from neighboring Finland), they are much stronger for migrants from more distant countries. Late arrival to the host country primarily leads to more frequent exposure to other migrants from the same country (rather than to immigrants in general), particularly at the marriage market, where preferences and social ties are likely to be particularly important. The strongest parental impact is found for female marriage patterns, which is consistent with daughters playing smaller roles as carriers of (origin country) culture for parents who have stayed longer in the host country. Cross-country exposure patterns also suggest the importance of linguistic and/or cultural similarity. However, we do not see any evidence of distinct critical periods, as is often found in studies of age at migration and learning, suggesting that language skills are not the sole determinant of the results.

The findings also suggest that youths who arrive earlier do not catch up over time, which implies that the effects of early life experiences on integration appear to be permanent. Overall, the results thus imply that early life experiences are formative. They have a profound impact on the patterns of future social interactions which cannot be explained by educational 
or economic outcomes, but which is consistent with theories of early formation of preferences and cultural identity.

The rest of the paper is outlined as follows. Section 2 describes the empirical setup. Section 3 describes the data and Section 4 presents some descriptive statistics on ethnicity and segregation in Sweden. Section 5 presents the results and Section 6 gives some concluding remarks.

\section{The empirical setup}

Our aim is to study the impact of childhood experiences and parental influences on social segregation at adulthood. To this end we use sibling differences in age at migration to get arguably exogenous variation in conditions encountered during childhood and adolescence. Below we describe an empirical model for estimating the impact of age at migration on outcomes measured at a fixed age at adulthood (in our case the early 30s). The model purports to establish a direct ("reduced-form”) relationship between age at migration and the outcome variables. In the results section we discuss their interpretation in more detail.

We define individual $i$ :s age at migration as the family's $(j)$ year of arrival $(C)$ minus the year of birth. As explained in the data section we use data where the family arrived between 10 years before and 14 years after the birth. Thus:

$$
\text { Age } e^{\operatorname{Im}} \equiv \text { Year of arrival }\left(C_{\mathrm{j}}\right)-\text { Year of birth } \in[-10,14]
$$

It is useful to start from the following conceptual model:

$$
y_{i j(i)}=\beta A g e_{i}^{\mathrm{Im}}+\delta_{t} T_{i}^{\text {Outcome }}+\gamma_{c} C_{j}^{\text {Arrival }}+u_{i j(i)}
$$

where $y_{i j(i)}$ is the outcome of individual $i$ belonging to family $j$. The outcome depends on a dummy variable for each possible age at migration (Age) except age 0 which serves as a reference point. $\beta$ is the corresponding vector of parameters, one for each age at migration. The model also accounts for effects from the calendar year of immigration $C$ and the year of observation $T$. Retrieving consistent estimates of the $\beta$ :s poses two challenges. First, as standard in the literature (see e.g. Borjas, 1999), we face a perfect linear dependency between 
age, cohort, and observation year. ${ }^{11}$ Second, we need to deal with the impact of potentially important unobserved heterogeneity. OLS estimates will confuse the impact of age at migration with an effect coming directly from the parents if e.g. parents who are particularly devoted to the success of their children adjust the timing of migration to the "optimal" age of the children. It is not unlikely that families who arrive with teenagers are fundamentally different from those who arrive with small children, or those who give birth to their children after arriving to the host country. Furthermore, both the timing of when to have children after migration and return migration choices may be influenced by the social and economic integration into the host country. ${ }^{12}$

In order to address these problems we first include family-specific fixed effects, $\alpha_{j}$, to handle unobserved heterogeneity. ${ }^{13}$ This means that we remove the impact of endogenous inmigration and endogenous out-migration, as well as associations related to the timing of child births as long as these are driven by factors at the family (rather than the child) level.

We measure age at migration by relating the birth year to the year the mother received her first residence permit (see the data section below for a discussion). This implies that year of arrival is constant within families by construction. Thus, the family fixed effect makes $C$ superfluous and we can therefore rewrite equation (2) as:

$$
y_{i j(i)}=\beta A g e_{i}^{\mathrm{Im}}+\delta_{t} T_{i}^{\text {Outcome }}+\alpha_{j}+\varepsilon_{i j(i)}
$$

Since outcomes are observed at a common age, the variation in age at immigration and time of observation is identical for siblings. This means that when including the family fixed effects, we have a perfect collinearity between age at migration and time of observation. A frequently used strategy to deal with this issue in the assimilation literature is to assume that observation time effects are the same for immigrants and natives. This approach is less appealing when studying social integration since the time effects are likely to differ between

\footnotetext{
${ }^{11}$ As is seen by replacing Year of birth in equation (1) by Year of outcome (T) minus "Age at outcome" where the latter is fixed by construction. Note though that the problem cannot be solved by looking at multiple outcome years.

${ }^{12}$ One could interpret higher fertility rates after immigration as indicative of selection, although they are commonly seen as a "disruption effect" in the demographic literature. See Mayer and Riphahn (2000) for a general discussion on economic and demographic models and empirical studies of fertility among immigrant women, and Andersson (2004) for Swedish evidence.

${ }^{13}$ The first paper to use sibling differences to isolate the effects of age at migration was Böhlmark (2008), who studied schooling outcomes. Van den Berg et al (2009) use a similar approach in their study of the relationship between age at migration and height at adulthood. Both of these papers are based on Swedish data.
} 
immigrants and natives, and has also been questioned in models of economic outcomes by e.g. Barth et al (2004) and Bratsberg et al. (2006).

In order to handle the effects of outcome years we instead propose a novel strategy using the outcomes of same-region age-zero migrants to identify calendar time effects. Below we first describe the procedure and then discuss the plausibility of the identifying assumptions. We begin by calculating the average outcome among same-aged immigrants who arrived at age 0 by observation year (and source region). Then we transform the data by deducting this average from the individual outcome. Formally, we deduct:

$$
\left.\bar{y}_{t}\right|_{A g e^{\mathrm{Im}}=0}=\delta_{t}+\left.\bar{\alpha}_{t}\right|_{A g e^{\mathrm{Im}}=0}
$$

from (3) to get

$$
\tilde{y}_{i j t}=\beta A g e_{i}^{\operatorname{Im}}+\alpha_{j}+u_{i j t}
$$

$$
\text { where } \tilde{y}_{i j t}=y_{i j t}-\left.\bar{y}_{t}\right|_{\text {age }=0} \text { and } u_{i j t}=\varepsilon_{i t}-\left.\bar{\alpha}_{t}\right|_{A g e^{\mathrm{Im}}=0}
$$

Equation (5) shows that identification is possible as long as the composition (in terms of the propensity for segregation) of immigrants arriving at age zero in different cohorts is uncorrelated with age at immigration within families. A sufficient condition for this to hold is that the composition of (i.e. propensity for segregation among) age zero immigrants is the same in all birth cohorts. In particular, one could worry that there is a time trend in segregation propensity. In order to test the assumption, we first predicted immigrant exposure on each of the three markets (see the following section for details on the data) using withinyear variation in region of birth (27 dummies, see Appendix A), education (7 dummies), age at child birth (with square) of fathers and mothers separately as well as birth order and gender of the child for the sample of age-zero migrants. In a second stage we analyzed the trend in predicted segregation. ${ }^{14}$ Reassuringly, in all cases the estimated time trend in predicted exposure was tiny and statistically insignificant for all three outcomes we study in this paper (0.00019 for workplaces, 0.00021 for neighborhoods, 0.00029 for marriages). The lack of a

\footnotetext{
${ }^{14}$ Since we calculate yearly exposure among age zero migrants separately for three broad country groups, we perform the second stage regressions controlling for the corresponding country group dummies.
} 
time trend is not particularly surprising considering that the between-year differences of equation (4) are identified from individuals who immigrated in the period 1960-1971 when labor migration consistently dominated the migrant inflow to Sweden (see below). In Section 5 we also discuss results building on alternative identifying assumptions.

In the family fixed effects model (5), identification of $\beta$ comes from differences between siblings in their age at the time when their parents immigrated. We augment this specification by a gender dummy and by including an indicator for being a first-born child,. ${ }^{15}$ An important issue is to what extent the impact on social integration operates via economic outcomes. To this end we also estimate specifications conditioning on education, employment, and wages in the outcome years. In order to analyze the role of potential catch-up over time, we study the age-integration profiles of groups arriving at different ages.

The introduction mentioned the importance of identifying the underlying mechanisms, in particular whether the effects are driven by differences in contact opportunities or by effects on preferences/choices given the same settings. We believe that the analysis to a very large degree excludes the first-mentioned mechanism, in particular by allowing for the possibility that siblings are exposed to different opportunity sets as a result of changes in population structure as well as changing overall behavior across cohorts through the procedure using same-region age-zero migrants. We also present specifications that condition on educational and economic outcomes which are important determinants of contact opportunities and discuss specifications controlling for the residential exposure of the parents close to the time of market entry for the subject (thus controlling for the possibility that it is their current situation that influences child outcomes).

We will present models capturing age at migration (years) in two different ways: (i) as dummies; (ii) using a spline function where the impact is assumed to be linear but where the slope is allowed to change at age 0 . Specification (i) is more flexible, whereas (ii) gives more precision and facilitates interpretation. The linear specification is also insensitive to potential measurement errors in time of immigration since these are shared between siblings (see Böhlmark, 2008).

\footnotetext{
${ }^{15}$ See e.g. Black et al (2005) and Åslund and Grönqvist (2009) for empirical evidence of birth order effects for economic outcomes.
} 


\section{Data}

We base our analysis on population-wide register data from the IFAU database, which builds on registers originally collected by Statistics Sweden. The main original sources are a residential register (RTB), a linked employer-employee database (RAMS), and an intergenerational register capturing links between parents and children (Flergenerationsregistret) as well as information on marital status from registers in the LOUISE database. All these registers are linked by means of a personal identification number used by all Swedish residents in contacts with employers and government agencies.

The dataset contains information on all individuals aged 16-65 living in Sweden at some point between 1985 and 2005. For these individuals we can identify region of birth, region of birth of each of the parents, year of immigration, ${ }^{16}$ gender, and year of birth. Furthermore, for each year we have information on place of residence, education, earnings, and an exhaustive list of employers (see more below). The intergenerational register also contains an indicator of each childbirth, the identity of the father and the mother, and the order of the child for each parent.

\subsection{Data restrictions}

Our sample contains all individuals born between 1960 and 1971 that either immigrated to Sweden before age 15 or whose parents immigrated 10 years or less before they were born. Thus, we measure age of immigration in the $[-10,14]$ interval and the included years of immigration span from 1950 to 1985. We concentrate on youths who arrived before age 15 to make sure that none of the subjects have entered the labor market or the marriage market before migrating. We define family fixed effects using the identity of the mother. We only include cases where none of the parents were born in Sweden. ${ }^{17}$ Age at immigration is (as discussed above) based on the year when the mother received her first residence permit. For children born in Sweden there is no alternative to using parental information. Using instead the child's first residence permit for immigrant children does not change the key results, but creates an asymmetry in definitions between children born just before and just after the family immigrated. In the baseline specifications we measure outcomes as averages of observations at ages 31-34; using several years to minimize the impact of missing values for labor market variables.

\footnotetext{
${ }^{16}$ We only have access to the last year of immigration during our sample period (1985-2005) and we use, for each individual, the first recorded "last year of immigration", i.e. for most individuals the year recorded in the 1985-file.

${ }^{17}$ Individuals where the mother is foreign-born and father data are missing are also included.
} 


\subsection{Outcome measures and markets}

Our main measure of integration/segregation is immigrant exposure defined as the fraction of others (within the neighborhood, the workplace or the marriage) that are foreign-born, i.e. the fraction of neighbors, co-workers, and spouses who are immigrants. This simple measure has the virtue of being defined at the individual level and is also highly correlated with more advanced segregation measures focusing on interactions (Echenique and Fryer 2007). Note that the individual him-/herself is excluded when calculating the measure. ${ }^{18}$

We only calculate how exposed the youths are to individuals actually born outside of Sweden although our study subjects also include native children with foreign-born parents. The reason is that we lack data on where parents of older individuals were born. Thus, we cannot calculate exposure to (older) "second-generation" immigrants. Although this choice reduces the level of measured exposure, it is unlikely to affect the patterns we are interested in. For visibility we define exposure in percent rather than fractions.

We use information about the mother's place of birth as a measure of origin and separately analyze the exposure to immigrants of similar origin (“own group”) and to immigrants of other origin ("other group"). The underlying information is grouped into 26 regions by Statistics Sweden for confidentiality reasons. The definitions of the regions can be found in the appendix.

We study interactions in three markets. The analysis of residential integration builds on data derived from the address where each individual is registered on the $31^{\text {st }}$ of December each year. This information is aggregated into neighborhoods referred to as SAMS (Small Area Market Statistics) areas by Statistics Sweden. In total there are 9,230 SAMS areas in Sweden, which means that approximately 1,000 individuals inhabit the average neighborhood. Our analysis only uses data on neighbors aged 16-64.

Our data on coworker exposure are constructed in the following way. We identify (through files based on tax records) all individuals employed at a particular establishment in November each year, counting only those earning at least 25 percent of the average janitor wage (i.e. a low cutoff) and only the job generating the highest wage for each individual and year. ${ }^{19} \mathrm{Co}-$ workers are others employed at the same workplace according to the definition above. Individuals employed at workplaces with only one employee, as well as those lacking a

\footnotetext{
${ }^{18}$ See Åslund and Skans (2009) for a discussion of the use of this measure in comparison to other potential segregation measures, and for references to the vast methodological literature on the measurement of segregation.

${ }^{19}$ See Åslund et al. (2009) for details on the definition of wages and employment. Skans et al (2009) use a similar procedure and show that the ensuing wage distribution is very similar to the actual distribution of monthly wages. The information on janitor wages are drawn from various publications by Statistics Sweden, detailed information is available upon request.
} 
stationary workplace (e.g. artists, freelance employees) do not have any co-workers by definition (about 5 percent of the sample). ${ }^{20}$

We measure exposure at the marriage market through the origin of the subject's spouse. An individual's spouse is defined using the following hierarchical criteria: (i) the partner in marriage if married; (ii) the cohabiting spouse if not married but cohabiting with common children; (iii) the other biological parent of the subject's first child if living alone but having a child (thus exploiting the multi-generational links in the data). Somewhat more than half (a quarter of) the sample is classified through the first (second) criterion. For ease of exposition, we henceforth use the term marriage for links between individual's that are based on any of these criteria.

The analysis is conditional on participation in the markets considered. For all markets we have the restriction that the individual must be living in Sweden at the time when the outcome is measured. This is the only restriction on the sample used for studying residential segregation. For the workplace and marriage segregation analyses we must also condition on being employed and married respectively. In the robustness checks we discuss potential selection biases in the results due to participation effects from age at migration.

\section{Description: Ethnic segregation in Sweden}

The early immigration waves to Sweden during the 1950s and 1960s mainly consisted of labor migrants from neighboring, but at the time much poorer, Finland as well as from Mediterranean countries such as Yugoslavia, Turkey, and Italy. From the early 1970s, immigration has shifted towards refugees and family reunification migrants. Substantial numbers have arrived from Chile, Turkey, Iran Somalia, former Yugoslavia, and Iraq. Finland is however still the largest source country in Sweden's immigrant population. The fraction of foreign-born is about 13 percent which is a high figure by international comparisons. Although a large share of the current immigrant inflow are from refugee countries, a large share of young adults with immigrant parents are descendants of earlier labor migrants.

The individuals included in our analysis are to a large extent part of the first-mentioned wave of relatively low-qualified labor migrants (see Table B1 in the appendix). The average years of schooling among parents are below $10 .^{21}$ Nordic migrants make up 60 percent of the

\footnotetext{
${ }^{20}$ The workplace indicators are defined from physical addresses of where people do the major part of their work.

${ }^{21}$ The fraction with missing information on parental education is high, but less of a concern given that the baseline analysis employs family fixed effects and does thus not use parental education as a control variable.
} 
sample, and within this group Finland constitutes 85 percent. Yugoslavia, Turkey, Germany and "Southern Europe" (i.e. Italy and Greece to a large extent) are other groups of significant size.

The poor relative labor market outcomes of immigrants and their children are a concern for Swedish policy makers, perhaps even more than in other countries (OECD 2009). Table 1 presents statistics which illustrate the situation quite well (even though they are limited to the birth cohorts of the main analysis). There are four groups in the table: Natives with native parents, natives with foreign-born parents (arriving less than 10 years before birth), immigrants arriving before age 15, and immigrants arriving later. The two intermediate populations make up the sample for the main analysis. All statistics are measured as averages at ages 31-34. A first observation is that the average level of education among immigrants, and children of immigrants, is similar to that of natives with native parents. Second, labor market performance is somewhat poorer among natives with foreign-born parents than among other natives, and a lot poorer among the foreign-born. As in other countries, there are substantial differences across origin groups (see e.g. Åslund and Skans 2010).

Turning to the degree of immigrant exposure, we find large immigrant-native differences within all three markets. Immigrants and natives would on average be equally exposed to people of immigrant (and native) background if there was no systematic sorting. ${ }^{22}$ Thus, the fact that we see more immigrant exposure among those with an immigrant background can be interpreted as evidence of segregation.

Segregation is also seemingly increasing in age at migration. Those with "foreign background" have more immigrants among their colleagues and neighbors, and do more often marry immigrants. ${ }^{23}$ The magnitudes are quite striking: those who immigrated as youths are more than twice as likely to have an immigrant spouse compared to those born in Sweden with two foreign-born parents (39 vs. 18 percent). Compared to natives with two native parents, immigrant youths are more than 5 times as likely to marry an immigrant.

\footnotetext{
${ }^{22}$ Note that the size of the average unit does not matter for this argument. The fact that marriages contain fewer individuals than a workplace or a neighborhood is thus not a concern. For example, let there be 10 percent immigrants in a country (and for simplicity think of this fraction as uniform across the age distribution). Then we would expect each person (independent of origin) to pick an immigrant spouse with a 10 percent probability. Likewise he or she would "pick" an immigrant coworker and an immigrant neighbor respectively with a 10 percent probability. Therefore we would find that both people with and without an immigrant background have (on average) 10 percent immigrants among their spouses, co-workers and neighbors. See Åslund and Skans (2009) for a further discussion on comparisons between random and actual allocation distributions in a similar setting.

${ }^{23}$ Note that the extremely high rate of mating with immigrants among those arriving after age 15 is likely to be driven by couples arriving together.
} 
An important and closely related question is how the levels of exposure in the different arenas correlate at the individual level. If there is perfect correlation, there is no point in analyzing them separately. But interestingly, the associations between residential, workplace, and marriage market exposure are modest (see Appendix C and Åslund et al. 2009). The correlation coefficients are in the order of 0.3 , and within families (i.e. the variation primarily used in the empirical analysis) it is less than 0.2 in all cases. In other words, people may be much more integrated in one dimension than in another.

-- Table 1 about here --

\section{Results}

This section presents the empirical results, beginning with the baseline reduced-form family fixed effects specifications. We also seek to establish the underlying mechanisms by investigating to what extent the effects work through economic outcomes, whether the results reflect an impact of early experiences or mirror ongoing assimilation, and to which extent the results are driven by exposure to countrymen as opposed to other migrants in the markets studied. The section is concluded by a discussion on potential confounding factors and robustness checks as well as an investigation of heterogeneous effects by gender, origin and parental education.

\subsection{Baseline results}

Figure 1 shows semi-parametric estimates from the family fixed effects specifications discussed in Section 2. The specification imposes no functional form on how age at migration affects segregation. In all cases we use immigration at the year of birth as the baseline. The upper row presents the unconditional reduced-form results. The lower row displays the estimates from specifications controlling for education, employment and wages. In order to gain precision we have estimated a more restrictive model using a functional form with two separate linear segments divided by a spline at age 0 ; the estimates are presented in Table 2. This linear sibling fixed effects model also has the advantage of being insensitive to potential measurement errors regarding immigration year, as originally pointed out by Böhlmark (2008).

Overall, the results show that the fractions of immigrants at the workplace, in the neighborhood, and among spouses all increase with age at migration. The relationships are stronger among the children who were born before the family migrated (i.e. age at migration $>0$ ). For this group we find semi-parametric estimates that are statistically different from zero 
for virtually all ages. The magnitudes of the point estimates are substantial. Arriving at age 10 instead of age 2 increases the fraction of immigrant neighbors by one-quarter ( 4 percentage points relative to a mean of 16 percent), and the probability to marry an immigrant increases by almost two-thirds (20 percentage points relative to a mean of 31 percent). These results imply that the within-family estimates are of the same magnitudes as the raw descriptive differences presented in Table 1 above. Although there is a tendency for the slope to be increasing with age there is also a clear impact at very low ages, e.g. between arriving at age 2 or 7, which sets the results apart from most studies of the impact of age at migration on language acquisition. ${ }^{24}$

As explained in Section 2, the model includes controls for birth order through a dummy for first-born children. The estimates of the dummy are $0.033,0.325$ and 0.069 respectively for the workplace, residential and marriage spline regressions. Only the estimate for residential segregation is statistically significant and the estimates never exceed that of being one year older at the time of migration. Thus, age at migration appears to be substantially more important than order of birth for the outcomes we study here.

Figure 1 also indicates that there is an impact of parental time in the host country for the children who were born after the family migrated (i.e. age at migration $<0$ ). Although the precision of the semi-parametric estimates is somewhat poorer for this group, the picture is confirmed by the highly significant linear estimates of Table 2. This suggests that there is inheritance in the integration process; the "host country capital” (very broadly defined) acquired by parents before the child is born seems to reduce segregation among their children when they become adults. The size of the estimates is about half that of the estimates for time spent in the country by childhood immigrants. The p-values for a test of the slope coefficients being the same for childhood migrants and children of immigrants reject the null for all three outcomes. Thus, the results suggest that roughly half of the integration due to earlier age at migration is an effect of parental integration and half is due to individual experiences (assuming linearity of the components).

-- Figure 1 about here -

-- Table 2 about here -

\footnotetext{
${ }^{24}$ This also differentiates the results from those of Bleakley and Chin (2010) who find that age at migration for those arriving before age 7 is uncorrelated with the language skills of the spouse chosen later in life. One possible explanation is that the effects for those arriving early mainly change the sorting patterns with respect to the spouse's cultural background (i.e. source country) rather than with respect to the spouse's language skills.
} 
A natural next question is to what extent the results operate via economic outcomes. As discussed above there is clear evidence on an impact from age at migration on education and on labor market outcomes. Results in Appendix C (see also Åslund et al. 2009) show that this holds also for our sample: education and employment both fall with age at migration. It seems plausible that part of the effect on social segregation could be due to e.g. poorer economic status restricting the choice of residential areas, or to people with less education having fewer opportunities to enter social arenas. The lower panel of Figure 1 and the right-hand side columns of Table 2 (denoted by B) show that conditioning on education, employment and wages in the regressions can explain part of the impact of age at migration on workplace segregation, but nothing of the effects on residential and marital sorting. Thus, most of the effect does not arise because children arriving at a younger age are more economically integrated in the host countries.

\section{Permanent effects of formative years, or delayed assimilation?}

Another central question for the interpretation of the findings is whether age at migration causes persistent differences in the integration, or if there is an ongoing assimilation process where outcomes eventually converge. In the specifications above, the estimates on age at migration may reflect both of these processes. To investigate the issue we estimate individual fixed effects models for residential and workplace exposure, using multiple outcome years in the age interval 25-34 for five groups classified according to age at migration. ${ }^{25}$ Since the outcome at the marriage market to a large extent is the result of a one-shot game, we focus on neighbors and coworkers (that change more often) in this analysis.

-- Figure 2 about here --

Figure 2 plots the estimated age profiles for individuals arriving at age $-10,-5,0,5$, and 10 respectively. The values decrease somewhat ( 0.1 to 0.2 percent per year) with age, suggesting that there is a tendency for childhood migrants and children of migrants to move from immigrant dense neighborhoods and workplaces into more integrated ones as they become older. But the slopes are very similar irrespective of age at migration and the differences across age-at-migration-groups are constant. Thus, the gradual integration we see appear to be due to a common age effect, rather than stemming from a declining effect of age at migration. This lack of catch-up among children arriving at a higher age implies that the effects found in the baseline analysis arise because of persistent factors that are set prior to

\footnotetext{
${ }^{25}$ We excluded marriage exposure since it only change with time as a consequence of divorce and remarriage, and does not change by definition for those whose partner is identified by being the parent of the first-born child.
} 
market entry and not because the individuals (and families) have had longer or shorter time to adapt to the host country when we observe them at adulthood.

A related issue is to what extent parental segregation at the time of market entry for the subject can explain the differences according to age at migration. Unfortunately we cannot measure residential segregation early on in life for the children. After restricting the number of included cohorts we have experimented with controlling for the parental residential exposure when the child is aged 19 or 25 respectively. This had very little effect on the results, suggesting that differences in the parental degree of integration in this dimension when children are relatively old do not influence later child outcomes.

\section{Separation from natives or ethnic clusters?}

To better understand the process of integration we separate exposure to immigrants from the same region of origin (“own-group” exposure) from exposure to other foreign-born ("othergroup” exposure). Skans and Åslund (2009) show that sorting along finer ethnic lines is substantially more prevalent in all the markets studied here. The question is then how sorting in the different dimensions is affected by age at migration; Table 3 presents estimates addressing this issue.

Age at migration affects both dimensions in the residential market, but relative to the sample mean the estimates are somewhat larger for own-group exposure. For workplace segregation, increased exposure to immigrants with the same origin is the dominating component, even though there is some influence on exposure to other immigrant groups. But the most striking finding is that, for marriages the entire effect of age at migration goes through the probability of finding a spouse from the mother's region of birth. Age at migration has no effect at all on the probability of finding a spouse of other immigrant origin.

Thus, overall, childhood migrants who spend less time in the host country as children appear to primarily become more exposed to others of a similar ethnicity, not to immigrants in general, compared to their siblings who spent more time in the host country as children. Somewhat stylized, the results therefore suggest that arriving late is a foundation for ethnic clustering, rather than a foundation for separation from natives into more general immigrant dense environments.

A stronger impact on own-group sorting is consistent with broadly defined ties to the source country as an important mechanism. This interpretation is also supported by Table B2 showing that cross-country exposure tends to be stronger across countries that share linguistic and cultural ties (e.g. "South American”-Chile and “Middle East"-Turkey). Another 
indication on the importance of preferences and ethnic identity is that we find the strongest patterns of within-group sorting at the marriage market, where cultural factors and preferences are likely to matter the most.

-- Table 3 about here --

\subsection{Heterogeneous effects: gender, origin, and parental education}

Table 4 displays estimates from sibling models where the effects of age at migration are allowed to vary between men and women. As a background, it is worth noting that Åslund and Skans (2005) report roughly equal levels of exposure to other immigrants among the two genders (24.8 percent for men and 22 percent for women), and a somewhat higher exposure to ethnic peers among men (7.7 percent) than among women (5.3 percent). The results in Table 4 suggest that male coworker exposure is more affected by early conditions than what is the case for females; the difference between men and women in the $(0,14)$ interval is statistically and economically significant. Interestingly, conditioning on economic outcomes decreases the male $(0,14)$ coefficient on workplace exposure by half, but only slightly reduces the association among women. ${ }^{26}$ In addition, estimates presented in Appendix C (see also discussion in Åslund et al. (2009)) show that employment and wages are more affected for males than for females. Jointly these findings suggest that early experiences have a larger impact on the labor market outcomes of males.

For marriages on the other hand, the estimates indicate that parental time in the host country is more influential on the daughters' choice of spouse. This is in line with psychological research arguing that females to a greater extent are expected to maintain the culture of the country of origin (Phinney et al. 2001, Warikoo 2005), since changes in parental attitudes should then be more likely to influence females. Interestingly, the effects are very similar across genders for children who migrated themselves. ${ }^{27}$

It is well known from previous research that labor market performance and social segregation vary heavily depending on region of origin. People of Nordic descent tend to manage best and be least segregated at the Swedish labor market, followed by other Western migrants, whereas Non-Westerners experience the biggest difficulties. This does not necessarily mean that the effects of early experiences are larger in the latter group. However,

\footnotetext{
${ }^{26}$ Note though that this specification conditions on wages which may be an endogenous variable in the workplace exposure regression.

${ }^{27}$ The first-born dummy is always statistically insignificant in the gender specific regressions.
} 
our analysis shows that they are indeed more pronounced for the non-western migrants although present independent of origin, and at all three markets. ${ }^{28}$

Another well-established phenomenon is the association between parental socioeconomic status and child outcomes. This is confirmed in our sample: education, employment and wages increase with mother's and father's education, whereas segregation decreases with higher parental status. Interestingly, the influence of the mother's and father's education is very similar except for in the marriage specification, where the education of the mother is much more influential (i.e. children of highly educated mothers marry natives more often). The impact on marriage exposure is -0.012 for each year of mother's education and -0.007 for each year of father's education. ${ }^{29}$ However, the impact of age at migration appears to be more or less independent of the parental level of education (full results available upon request).

-- Table 4 about here -

\subsection{Robustness checks}

\section{Participation effects}

A first concern regarding the marriage and workplace results is that they are conditional on participation in the studied markets. As discussed above, employment is related to age at migration. If anything, this is likely to give a negative bias in the estimates for immigrant workplace exposure. Immigrant dense workplaces pay low wages (Åslund and Skans 2010) and a positive selection on unobserved characteristics will arguably mean a lower fraction in these establishments. We would then underestimate the segregation tendency among those who were older at entry to Sweden.

The data used here suggest that there are participation effects in the marriage market as well: arriving one year later increases the probability of having a spouse by about 1 percentage point, which should be related to the average marriage rate of 31 percent (results available upon request). Homogamy is also more common among those who find a spouse early, suggesting a positive correlation between the inclination to marry and to choose a partner of immigrant descent. ${ }^{30}$ Thus, the fewer the married in one "age-at-migration” pool, the higher the unobserved propensity for homogamy among those who are married. This

\footnotetext{
${ }^{28}$ The effects on workplace (residential; marriage) exposure in the $0-14$ interval is $0.78(0.64$; 3.1$)$ for migrants of nonwestern origin and $0.23(0.05 ; 0.79)$ for migrants from the neighboring Nordic countries (dominated by Finland).

${ }^{29}$ This result can be related to Casey and Dustmann (2010) who find that mothers are mostly influential in transferring a home country identity. Our results suggest that the influence also varies greatly depending on the mother's socioeconomic position.

${ }^{30} 50$ (28) percent among those who marry at age 19 (24) have an immigrant partner. A linear regression of the probability of homogamy on age at marriage yields a point estimate (s.e.) of $-0.036(0.001)$.
} 
would in turn reduce the observed difference in the probability of homogamy between early and late arrivals, since a larger fraction of the latter group is married at a given age.

\section{Alternative identification strategies}

As discussed in Section 2, a central methodological challenge is how to control for observation time effects. An alternative to the baseline approach is to control for observation year effects directly (ignoring arrival cohort dummies), and parameterize the effects of family background (i.e. to control for e.g. parental education and country of origin) instead of using family fixed effects (recall that these implicitly control for year of arrival). The identifying assumption is then that conditional on the included covariates and observation year, there is no bias due to a correlation between age at migration and unobserved background characteristics and/or immigration year.

Appendix C presents results from this exercise (see also Åslund et al. (2009)). A first message is that OLS estimates for the sibling sample (i.e. excluding family fixed effects) are very similar to those of the full sample. This suggests that the sibling sample is representative for immigrant youth in general. Secondly, the estimates for the age at arrival interval $(0,14)$ are stable across approaches. But we also find that the estimated exposure effects are smaller in the $(-10,0)$ interval when family fixed effects are left out, signaling stronger selection effects on the timing of child births in the host country than in the decision to migrate (conditional on the covariates included in the alternative specification). This is not so surprising: Whereas migration may be triggered by "now or never" job opportunities or sudden push factors, there is likely to be more scope for adjusting the timing of births once in the host country. The direction of the bias suggests that parents who are more "prone" to segregation on average spend a longer time in the host country before giving birth. One explanation may be that parents who have a (sometimes never realized) wish to return the country of origin wait longer before giving birth and have stronger preferences for living with other immigrants. If children inherit these preferences from their parents we would expect a bias in the observed direction. ${ }^{31}$

We have also experimented with further alternatives for controlling for observation time effects in the sibling analysis. Controlling for the pool of countrymen gives similar patterns for workplace and residential exposure, and including controls for the number of immigrants

\footnotetext{
${ }^{31}$ Another alternative is that people do not have children until their economic situation is sufficiently stable. If a tendency to live and work with immigrants is correlated with (or caused by) labor market potential, we would also see this pattern. Furthermore, the family fixed effects capture immigration cohort effects which might also bias the OLS results.
} 
of the opposite gender from the same source country does not alter the patterns for the marriage results. All results are also robust to exclusions of siblings who are born more than five years apart.

\section{Conclusions}

This paper studies how early life experiences affect integration in adulthood among childhood migrants and children of immigrants. We quantify integration by measuring the origin among the people surrounding the subject at three different important social arenas. We get estimates of the role of age at migration and parental pre-birth time spent in the host country by exploiting sibling variation in age at migration using population-wide multigenerational Swedish data.

Our results show that age at migration has a substantial effect on the integration of young migrants.. For example, being ten years old instead of two years old at the time of migration increases the fraction of immigrants among colleagues and neighbors by about one quarter to one fifth of the average in the sample. The effects are even stronger in the marriage market; in the same comparison, the probability to marry another immigrant increases by almost two thirds of the average homogamy rate in the sample. As a comparison, the effect of arriving a single year later is always much larger than the effect of being the first-born child in a family. The effects of age at migration are gradual, starting at a very young age. Even though there is some evidence of an increased slope with age, there is no evidence of a specific critical age as is often found in studies focusing on language skills. We also find that parental time spent in the host country prior to the subject's birth matters for the outcomes of children of immigrants. The effect from parental assimilation is not as strong as from own experiences, but highly significant which clearly suggest that integration is inherited across generations.

Our analysis also shows that the effects are unlikely to be driven by processes related to skills or economic outcomes since conditioning on individual education, employment, and wages has little impact on the estimated effect of age at arrival. Neither does it seem to be the case that the results reflect different phases of an ongoing social assimilation process, since the integration-age profiles are parallel between groups arriving at different ages. This also implies that the effects are likely to be highly persistent. Furthermore, the results do not appear to reflect differences in parental integration at the time of the individual's market entry. Taken together, these findings suggest that differences in contact opportunities are unlikely to be the main driving mechanism. 
Instead, the results point to the conclusion that preferences or influential cultural factors formed at early ages are important. Most of the effects arise through increased exposure to other migrants of a similar origin, rather than towards other immigrant groups. The effects thus seem to be driven by ties to the individual's ethnic group, and not as much by an increased divide relative to the native population. The effects tend to be greater among migrants from more distant countries, which suggests that time is more important if the initial cultural distance is greater. The finding that factors long before school start matter, in sharp contrast to the findings in the literature which focuses on language acquisition, suggest that language skills is not the main determinant. The fact that marriage patterns are the outcome which is most strongly affected by parental time in the host country (in particular for girls) is consistent with explanations where the social adaptation and acculturation of parents primarily feed onto the children's outcomes in areas where preferences matter the most. It is also consistent with the gendered patterns of cultural transmission found in previous studies.

Overall, our study shows that segregation-shaping behavior and decisions in adulthood are strongly influenced by events and environmental factors experienced at early ages. Recent findings suggest that ethnic identity is not a crucial determinant of economic and educational differences (Battu and Zenou 2010, Casey and Dustmann 2010, Nekby and Rödin 2010) whereas our results suggest that cultural identity, broadly defined, may be an important determinant of segregation. The two sets of results are consistent in the sense that our analysis suggests that economic variables only play a marginal role in transmitting the effects of cultural identity into social segregation. Understanding the development of social ties and feelings of connection thus appears important for predicting the extent of future fragmentation of societies with increasing ethnic heterogeneity. 


\section{References}

Algan, Y., C. Dustmann, A. Glitz and A Manning (2010) "The Economic Situation of First and Sceond-Generation Immigrants in France, Germany and the UK”, Economic Journal vol. 120 no. 542, F4-F30.

Andersson, G. (2004) "Childbearing after Migration: Fertility Patterns of Foreign-born Women in Sweden”, International Migration Review Volume 38 Number 2 (Summer 2004):747-775.

Åslund, O, A. Böhlmark and O.N. Skans (2009) “Age at Migration and Social Integration”, IZA DP No. 4263.

Åslund, O. and O.N. Skans (2005) "Will I See You at Work? Ethnic Workplace Segregation in Sweden 1985-2002”, IFAU Working Paper 2005:04.

Åslund, O. and O.N. Skans (2009) "How to measure segregation conditional on the distribution of covariates”, Journal of Population Economics 22(4), 971-981.

Åslund, O. and O.N. Skans (2010) "Will I See You at Work? Ethnic Workplace Segregation in Sweden 1985-2002”, Industrial and Labor Relations Review 63(3).

Austen-Smith, D. and R.G. Fryer (2005) “An Economic Analysis of "Acting White”, Quarterly Journal of Economics, Volume 120, Number 2 (May 2005), pp. 551-583

Barth E, B. Bratsberg and O. Raaum (2004) "Identifying Earnings Assimilation of Immigrants under Changing Macroeconomic Conditions” Scandinavian Journal of Economics 106 (1), $1-22$.

Battu, H. and Y. Zenou (2010) "Oppositional Identities and Employment for Ethnic Minorities: Evidence from England”, Economic Journal vol. 120 no. 542, F52-F71.

Bisin, A. and T. Verdier (2000) “"Beyond The Melting Pot”: Cultural Transmission, Marriage, And The Evolution Of Ethnic And Religious Traits”, Quarterly Journal of Economics August 2000, Vol. 115, No. 3, 955-988.

Bisin, A. and T. Verdier (2001) "The Economics of Cultural Transmission and the Dynamics of Preferences”, Journal of Economic Theory, 97, 298-319.

Bisin A., E. Patacchini, T. Verdier and Y. Zenou (2006) “'Bend It Like Beckham’: Identity, Socialization, and Assimilation”, CEPR Discussion Paper No. 5662.

Bleakley H. and A. Chin (2008) "What Holds Back the Second Generation?: The Intergenerational Transmission of Language Human Capital Among Immigrants," Journal of Human Resources, vol. 43(2), pages 267-298.

Bleakley H. and A. Chin, (2010) "Age at Arrival, English Proficiency, and Social Assimilation among US Immigrants." American Economic Journal: Applied Economics, 2(1): 165-92.

Böhlmark A (2008) “Age at Immigration and School Performance: A Siblings Analysis Using Swedish Register Data”, Labour Economics 15(6), 1366-1387.

Böhlmark, A. (2009) "Integration of Childhood Immigrants in the Short and Long Run Swedish Evidence”, International Migration Review 43(2), 387-409.

Borjas, G.J. (1999) “The Economic analysis of immigration” in Ashenfelter O., R. Layard and D. Card, Handbook of Labor Economics, edition 1, volume 3, chapter 27, pages 15591695, Elsevier. 
Bråmå, Å. (2006) Studies in the Dynamics of Residential Segregation, PhD Thesis Uppsala University, Faculty of Social Sciences, Department of Social and Economic Geography.

Bratsberg, B., E. Barth and O. Raaum (2006) "Local Unemployment and the Relative Wages of Immigrants: Evidence from the Current Population Surveys" Review of Economics and Statistics May 2006, Vol. 88, No. 2, 243-263.

Carlsson, M (2009) Essays on Discrimination in Hiring, PhD Thesis, Acta Wexionensia no 189/2009, Växjö University Press.

Casey T and C Dustmann (2010) “Immigrants' Identity, Economic Outcomes and the Transmission of Identity Across Generations”, Economic Journal vol. 120 no. 542, F31F51.

Chiswick, B. and N. DebBurman (2004). "Educational attainment: Analysis by immigrant generation” Economics of Education Review, 23, 361-379.

Clark, K. and S, Drinkwater (2007) "Segregation preferences and labor market outcomes" Economics Letters 94 (2), 278-283.

Cortes, K. (2006) "The Effects of Age at Arrival and Enclave Schools on the Academic Performance of Immigrant Children", Economics of Education Review 25 (2006) 121-132.

Cunha F, J. Heckman, L. Lochner and D. Masterov (2007) "Interpreting the Evidence on Life Cycle Skill Formation” in Hanushek E and F Welch (eds) Handbook of the Economics of Education, Volume 1, Elsevier.

DiPrete T.A., A. Gelman, T. McCormick, J. Teitler and T. Zheng (2011) "Segregation in Social Networks Based on Acquaintanceship and Trust" American Journal of Sociology Vol. 116, No. 4 (January 2011), pp. 1234-83.

Dribe, M. and C. Lundh (2008) "Intermarriage and Immigrant Integration in Sweden”, Acta Sociologica, Vol. 51, No. 4, 329-354.

Echenique F and RG Fryer (2007), “A Measure of Segregation Based on Social Interactions”, Quarterly Journal of Economics 122(2), 441-485.

Erikson, E.H. (1968). Identity: Youth and Crisis. New York: Norton.

Fernandez R., A. Fogli and C. Olivetti (2004) "Mothers and Sons: Preference Formation and Female Labor Force Dynamics”, Quarterly Journal of Economics 119(4), pp 1249-1299.

Fordham, S. and J.U. Ogbu (1986) “Black Students’ School Success: Coping with the Burden of 'Acting White”, Urban Review, 18: 176-206.

Fryer R.G. and P. Torelli (2005) “An Empirical Analysis of `Acting White'”, NBER Working paper 11334.

Gonzalez, A. (2003). "The education and wages of immigrant children: The impact of age of arrival” Economics of Education Review, 22, 203-212.

Hellerstein, J. and D. Neumark (2008), "Workplace Segregation in the United States: Race, Ethnicity, and Skill.”, Review of Economics and Statistics Vol. 90, No. 3, 459-477.

Iceland J., D.H. Weinberg and E. Steinmetz (2002) Racial and Ethnic Residential Segregation in the United States: 1980-2000, U.S. Census Bureau, Series CENSR-3, U.S. Government Printing Office, Washington, DC, 2002.

Kalmijn, M. (1998) "Intermarriage and Homogamy: Causes, Patterns, Trends” Annual Review of Sociology 1998 24, 395-421. 
Kao, G., and M Tienda (1995). "Optimism and achievement: The educational performance of immigrant youth”. Social Science Quarterly, 76, 1-19.

Kossinets, G. and D.J. Watts (2009) “Origins of Homophily in an Evolving Social Network”,

American Journal of Sociology Vol. 115, No. 2 (September 2009), pp. 405-450

Lazear, E. (1999) “Culture and Language”, Journal of Political Economy 107(6), 95-126.

Lubotsky D (2007) “Chutes or Ladders? A Longitudinal Analysis of Immigrant Earnings” Journal of Political Economy 115:5, 820-867

Marks, A. K., LA Szalachab, M Lamarre, MJ Boydd, and C García Coll (2007) "Emerging ethnic identity and interethnic group social preferences in middle childhood: Findings from the children of immigrants development in context (CIDC) study" International Journal of Behavioral Development, vol. 31(5), pp. 501-513.

Mayer, J. and R.T. Riphahn (2000) "Fertility assimilation of immigrants: Evidence from count data models”, Journal of Population Economics (2000) 13: 241-261.

McPherson, J.M. and L. Smith-Lovin (1987) "Homophily in Voluntary Organizations: Status Distance and the Composition of Face-to-Face Groups" American Sociological Review, Vol. 52, No. 3 (Jun., 1987), pp. 370-379

McPherson J.M, L. Smith-Lovin, J.M. Cook (2001) "Birds of a Feather: Homophily in Social Networks” Annual Review of Sociology Vol 27, pp. 415-444.

Nekby L and M Rödin (2010) "Acculturation Identity and Employment among Second and Middle Generation Immigrants", Journal of Economic Psychology, Vol. 31(1), pp. 35-50.

Nordin M and D-O Rooth (2009) "The Ethnic Employment and Income Gap in Sweden: Is Skill or Labor Market Discrimination the Explanation?”, The Scandinavian journal of economics 111(3), 487.

OECD (2009) "Children Of Immigrants in the Labour Markets of EU and OECD Countries: An Overview”, DELSA/ELSA/WD/SEM(2009)25, OECD Social, Employment and Migration Working Papers.

Phinney J.S., G. Horenczyk, K Liebkind and P. Vedder (2001) "Ethnic Identity and Wellbeing: An Interactional Perspective”, Journal of Social Issues 57(3), 493-510.

Portes, A. and P. Fernandez-Kelly (2008) "No Margin for Error: Educational and Occupational Achievement among Disadvantaged Children of Immigrants", The ANNALS of the American Academy of Political and Social Science, Vol. 620, No. 1, 12-36.

Qian, Z. and D.T. Lichter (2001) "Measuring Marital Assimilation: Intermarriage among Natives and Immigrants”, Social Science Research 30, 289-312.

Riphahn, R.T. (2001). "Cohort effects in the educational attainment of second-generation immigrants in Germany. An analysis of census data”. IZA Discussion Paper Series, No. 291.

Rivkin, S.G. (2000) “School Desegregation, Academic Attainment, and Earnings”, Journal of Human Resources, Vol. 35, No. 2. (Spring, 2000), 333-346.

Rooth, D-O. and J. Ekberg (2003) "Unemployment and earnings for second generation immigrants in Sweden. Ethnic background and parent composition”, Journal of Population Economics 16(4), 787-814. 
Saez-Marti, M. and A. Sjögren (2008) "Peers and Culture” , Scandinavian Journal of Economics, vol 110(1), 73-92.

Schaafsma, J. and A. Sweetman (2001). "Immigrant earnings: Age at arrival matters" Canadian Journal of Economics, 34, 1066-1099.

Skans, N. O. and O. Åslund (2009) Segregationen i storstäderna [Segregation in the Metropolitan areas], SNS Välfärdsrapport 2009, SNS Förlag, 108 pp.

Skans O.N., P-A. Edin and B. Holmlund (2008), "Wage dispersion between and within plants: Sweden 1985-2000” in Lazear E and K Shaw (red) Wage Structure, Raises and Mobility: International Comparisons of the Structure of Wages Within and Across Firms, University of Chicago Press. Available as NBER Working Paper 13021.

Tezic, K (2004), Essays on Immigrants' Economic Integration, PhD thesis, Economic studies 134, Department of Economics, School of Economics and Commercial Law

Thornton, A, F.A. Duane, and D. Camburn, "Causes and Consequences of Sex-Role Attitudes and Attitude Change,” American Sociological Review, XLVIII (1983), 211-227.

van den Berg, G.J., P. Lundborg, P. Nystedt and D-O. Rooth (2009), "Critical Periods During Childhood and Adolescence: A Study of Adult Height Among Immigrant Siblings” IZA Discussion Paper, no 4140.

Van Ours, J. and J. Veenman (2006) "Age at immigration and educational attainment of young immigrants”, Economics Letters 90 (2006) 310-316.

Waldinger, R. and C. Feliciano (2004) "Will the new second generation experience 'downward assimilation'? Segmented assimilation re-assessed” Ethnic and Racial Studies, Vol. 27 No. 3 May 2004 pp. 376-402.

Warikoo, N. (2005). 'Gender and ethnic identity among second-generation Indo-Caribbeans'.' Ethnic and Racial Studies, vol. 28(5), pp. 803- 831.

Weiland, A. and R Coughlin (1979). 'Self-identification and preferences: a comparison of White and Mexican American first and third graders.' Journal of Cross-Cultural Psychology, vol. 10, pp. 356-365.

Zhou, M. (1997) "Growing Up American: The Challenge Confronting Immigrant Children and Children of Immigrants”, Annual Review of Sociology 1997 23, 63-95 


\section{Appendix A: Birth regions}

\begin{tabular}{|c|c|}
\hline Region & Countries included \\
\hline Sweden & 0-Sweden \\
\hline \multirow[t]{3}{*}{ Nordic } & 1-Finland \\
\hline & 2-Denmark \\
\hline & 3-Norway+ Iceland \\
\hline \multirow{5}{*}{$\begin{array}{l}\text { Western Europe } \\
\text { and North America }\end{array}$} & $4-G B+$ Ireland \\
\hline & 5-Germany \\
\hline & $\begin{array}{l}\text { 6-Mediterr. Europe }(\text { Greece + Italy }+ \text { Spain }+ \text { Portugal }+ \text { the Vatican }+ \text { Monaco + Malta + } \\
\text { San Marino })\end{array}$ \\
\hline & $\begin{array}{l}\text { 7-Other Europe }(\text { Andorra }+ \text { Belgium }+ \text { France }+ \text { Liechtenstein }+ \text { Luxemburg }+ \text { the } \\
\text { Netherlands }+ \text { Switzerland }+ \text { Austria })\end{array}$ \\
\hline & 8-US + Canada \\
\hline \multirow[t]{6}{*}{ Eastern Europe } & 9-Bosnia-Herzegovina \\
\hline & 10-Former Yugoslavia (Yugoslavia + Croatia + Macedonia + Slovenia) \\
\hline & 11-Poland \\
\hline & 12-The Baltic states (Estonia + Latvia + Lithuania) \\
\hline & 13-Eastern Europe 1 (Rumania + The former USSR + Bulgaria + Albania) \\
\hline & 14-Eastern Europe 2 (Hungary + The former Czechoslovakia) \\
\hline \multirow[t]{13}{*}{ The rest of the world } & 15-Mexico and Central America \\
\hline & 16-Chile \\
\hline & $\begin{array}{l}\text { 17-Other South America (Argentina + Bolivia + Peru + Colombia + Uruguay + Ecuador + } \\
\text { Guyana + Paraguay + Surinam + Venezuela) }\end{array}$ \\
\hline & 18-African Horn (Ethiopia + Somalia +Sudan + Djibouti), \\
\hline & $\begin{array}{l}\text { 19- North Africa + Middle East (Lebanon + Syria + Morocco + Tunisia + Egypt + Algeria + } \\
\text { Israel + Palestine + Jordan + South Yemen + Yemen + the United Arab Emirates + Kuwait } \\
\text { + Bahrain + Qatar + Saudi Arabia + Cyprus) }\end{array}$ \\
\hline & 20- Other African (all African countries not included elsewhere) \\
\hline & 21-Iran \\
\hline & 22-Iraq \\
\hline & 23-Turkey \\
\hline & 24-East Asia (Japan + China + Korea + Hong Kong + Taiwan) \\
\hline & $\begin{array}{l}\text { 25-Southeast Asia (Vietnam + Thailand + the Philippines + Malaysia + Laos + Burma + } \\
\text { Indonesia + Singapore) }\end{array}$ \\
\hline & $\begin{array}{l}\text { 26-Other Asia }(\text { Sri Lanka + Bangladesh + India + Afghanistan + Pakistan + Brunei + Bhutan } \\
+ \text { Kampuchea + the Maldives + Mongolia + Nepal + Oman + Sikkim })\end{array}$ \\
\hline & 27-Oceania (Australia + New Zealand etc...) \\
\hline
\end{tabular}




\section{Appendix B: Descriptive statistics}

Table B 1 Description of the sibling sample

\begin{tabular}{|c|c|c|c|c|c|}
\hline Variable & Obs & Mean & Std. Dev. & Min & Max \\
\hline Year of birth & 47,890 & 1965.5 & 3.216 & 1960 & 1971 \\
\hline Immigration year & 47,890 & 1967.2 & 5.895 & 1950 & 1984 \\
\hline Age at migration & 47,890 & 1.742 & 5.675 & -10 & 14 \\
\hline Female & 47,890 & .487 & .500 & 0 & 1 \\
\hline Oldest & 47,890 & .328 & .470 & 0 & 1 \\
\hline Education & 47,625 & 11.52 & 1.963 & 8 & 19 \\
\hline Employment & 47,890 & 69.3 & 38.0 & 0 & 1 \\
\hline Log Wage & 36,753 & 9.498 & .473 & 7.923 & 12.023 \\
\hline Mother's schooling & 40,279 & 9.707 & 2.085 & 8 & 19 \\
\hline $\begin{array}{l}\text { Father's schooling } \\
\text { Mother's schooling }\end{array}$ & 31,584 & 9.889 & 2.271 & 8 & 19 \\
\hline $\begin{array}{l}\text { missing } \\
\text { Father's schooling }\end{array}$ & 47,890 & .159 & .366 & 0 & 1 \\
\hline missing & 47,890 & .340 & .473 & 0 & 1 \\
\hline \multicolumn{6}{|l|}{ Origin: } \\
\hline Finland & 47,890 & .561 & .496 & 0 & 1 \\
\hline Other Nordic & 47,890 & .094 & .292 & 0 & 1 \\
\hline Germany & 47,890 & .037 & .189 & 0 & 1 \\
\hline Western Europe & 47,890 & .017 & .129 & 0 & 1 \\
\hline Turkey & 47,890 & .053 & .225 & 0 & 1 \\
\hline Eastern Europe & 47,890 & .037 & .188 & 0 & 1 \\
\hline Yugoslavia & 47,890 & .010 & .300 & 0 & 1 \\
\hline Southern Europe & 47,890 & .039 & .193 & 0 & 1 \\
\hline Rest of the world & 47,890 & .061 & .240 & 0 & 1 \\
\hline \multicolumn{6}{|l|}{ Outcomes: } \\
\hline Workplace & 32,696 & 16.1 & 18.3 & 0 & 100 \\
\hline Residential & 47,890 & 19.5 & 15.1 & 0 & 95.6 \\
\hline Marriage & 29,685 & 30.6 & 46.1 & 0 & 100 \\
\hline
\end{tabular}

Notes: Values are for the sibling sample included in the "Residential" estimations, i.e. the sample with the highest number of observations. Education is years of schooling based on information on highest completed education. Employment is defined as passing a threshold, corresponding to $25 \%$ of the average janitor wage, for monthly earnings from one employer in a spell covering November. Wages are average monthly earnings in this spell. See Skans et al. (2009) and Åslund et al. (2009) for details. 


\begin{tabular}{|c|c|c|c|c|c|c|c|c|c|c|c|c|c|c|c|c|}
\hline \multirow{2}{*}{$\begin{array}{r}\text { Spouse region of } \\
\text { birth }\end{array}$} & \multicolumn{16}{|c|}{ Mother's region of birth } \\
\hline & (a) & (b) & (c) & (d) & (e) & (f) & (g) & (h) & (i) & (j) & $(\mathrm{k})$ & (l) & $(\mathrm{m})$ & (n) & (o) & (p) \\
\hline (a) Finland & 67.2 & 15.8 & 19.0 & 2.1 & 4.6 & 17.8 & 4.0 & 9.3 & 9.4 & 4.5 & 2.7 & 1.0 & 0.5 & 1.9 & 0.3 & 0.5 \\
\hline (b) Denmark & 1.5 & 29.1 & 3.7 & 1.4 & 3.9 & 6.5 & 0.8 & 2.0 & 3.3 & 0.2 & 0.5 & 0.2 & 0.1 & 0.6 & 0.6 & 0.5 \\
\hline (c) Norway + Iceland & 2.8 & 6.7 & 27.2 & 0.5 & 1.4 & 7.9 & 0.7 & 0.7 & 4.9 & 1.0 & 1.6 & 0.2 & 0.1 & 1.2 & & 1.0 \\
\hline (d) Fm Yugoslavia & 1.8 & 5.5 & 3.4 & 76.1 & 3.9 & 5.6 & 3.5 & 13.2 & 8.8 & 1.2 & 3.3 & 0.6 & 0.1 & & & 0.5 \\
\hline (e) Poland & 1.1 & 4.2 & 3.7 & 1.2 & 61.5 & 5.1 & 1.4 & 20.5 & 3.6 & 1.2 & & 0.2 & 0.1 & 0.6 & 0.3 & \\
\hline $\begin{array}{l}\text { (f) Germany } \\
\text { (g) Mediterranean }\end{array}$ & 1.1 & 1.2 & 1.9 & 0.7 & 1.4 & 12.1 & 3.6 & 1.3 & 2.6 & 0.2 & 1.1 & & 2.2 & & & 0.5 \\
\hline Europe & 2.2 & 3.6 & 3.4 & 1.6 & 2.8 & 7.0 & 71.2 & 4.0 & 3.3 & 2.4 & 4.9 & 0.6 & 0.6 & 1.2 & & 0.5 \\
\hline $\begin{array}{l}\text { (h) South East Europe } \\
\text { (i) Central Eastern }\end{array}$ & 0.7 & 2.1 & 0.4 & 1.3 & 1.6 & 1.9 & 1.7 & 23.8 & 3.6 & 1.4 & & 1.0 & 0.3 & 0.6 & & 0.5 \\
\hline Europe & 0.6 & 1.8 & 1.1 & 1.3 & 1.4 & 3.3 & 0.8 & 3.3 & 37.5 & 0.4 & & & 0.1 & 0.6 & & \\
\hline (j) Chile & 2.5 & 3.3 & 2.6 & 0.7 & 1.6 & 2.8 & 1.9 & 1.3 & 0.7 & 65.4 & 27.3 & 1.4 & 0.1 & 0.6 & 1.9 & \\
\hline (k) South America & 1.5 & 2.4 & 4.9 & 1.1 & 0.5 & 2.3 & 1.1 & 1.3 & 2.3 & 9.7 & 43.2 & 0.8 & 0.2 & & & 0.5 \\
\hline (l) M East + N Afr & 2.8 & 2.1 & 3.4 & 1.1 & 1.4 & 5.1 & 1.9 & 4.0 & 2.9 & 1.6 & 1.6 & 73.2 & 16.9 & & 0.3 & \\
\hline (m) Turkey & 1.0 & 1.8 & 1.9 & 1.7 & 0.7 & 0.9 & 0.9 & 3.3 & 1.3 & 1.0 & & 12.5 & 76.1 & 0.6 & 1.0 & 3.1 \\
\hline (n) East Asia & 0.9 & 0.6 & 1.9 & 0.0 & 0.7 & 2.8 & 0.3 & & 1.0 & 0.8 & 0.5 & 0.2 & 0.0 & 52.5 & 8.4 & 1.5 \\
\hline (o) SE Asia & 2.6 & 3.9 & 4.5 & 0.5 & 1.1 & 2.8 & 0.4 & 0.7 & 0.7 & 1.2 & & 0.6 & 0.1 & 22.8 & 76.0 & 8.2 \\
\hline (p) Other Asia & 0.8 & 1.5 & 0.7 & 0.2 & 0.5 & 1.9 & 0.3 & 0.7 & 0.7 & 0.2 & 0.5 & & 0.1 & 2.5 & 4.5 & 74.7 \\
\hline
\end{tabular}

Notes: The table shows fractions of marriages with non-natives by mother's region of birth and spouse's birth region. The samples are restricted to regions where we observe at least 100 marriages. To save space, the same restriction is used for spouse's birth region. 


\section{Appendix C: Supplementary results}

Below we present supplementary results, mentioned in the main text but discussed in detail in the working paper version Åslund et al. (2009).

Table C1 The correlation between the outcome measures.

\begin{tabular}{|c|c|c|c|}
\hline & \multicolumn{3}{|c|}{ Overall correlations } \\
\hline & Workplace & Residential & Marriage \\
\hline Workplace & 1 & -- & -- \\
\hline Residential & 0.34 & 1 & -- \\
\hline \multirow[t]{3}{*}{ Marriage } & 0.29 & 0.39 & 1 \\
\hline & \multicolumn{3}{|c|}{ Within-family correlations } \\
\hline & Workplace & Residential & Marriage \\
\hline Workplace & 1 & -- & -- \\
\hline Residential & 0.14 & 1 & -- \\
\hline Marriage & 0.12 & 0.18 & 1 \\
\hline
\end{tabular}



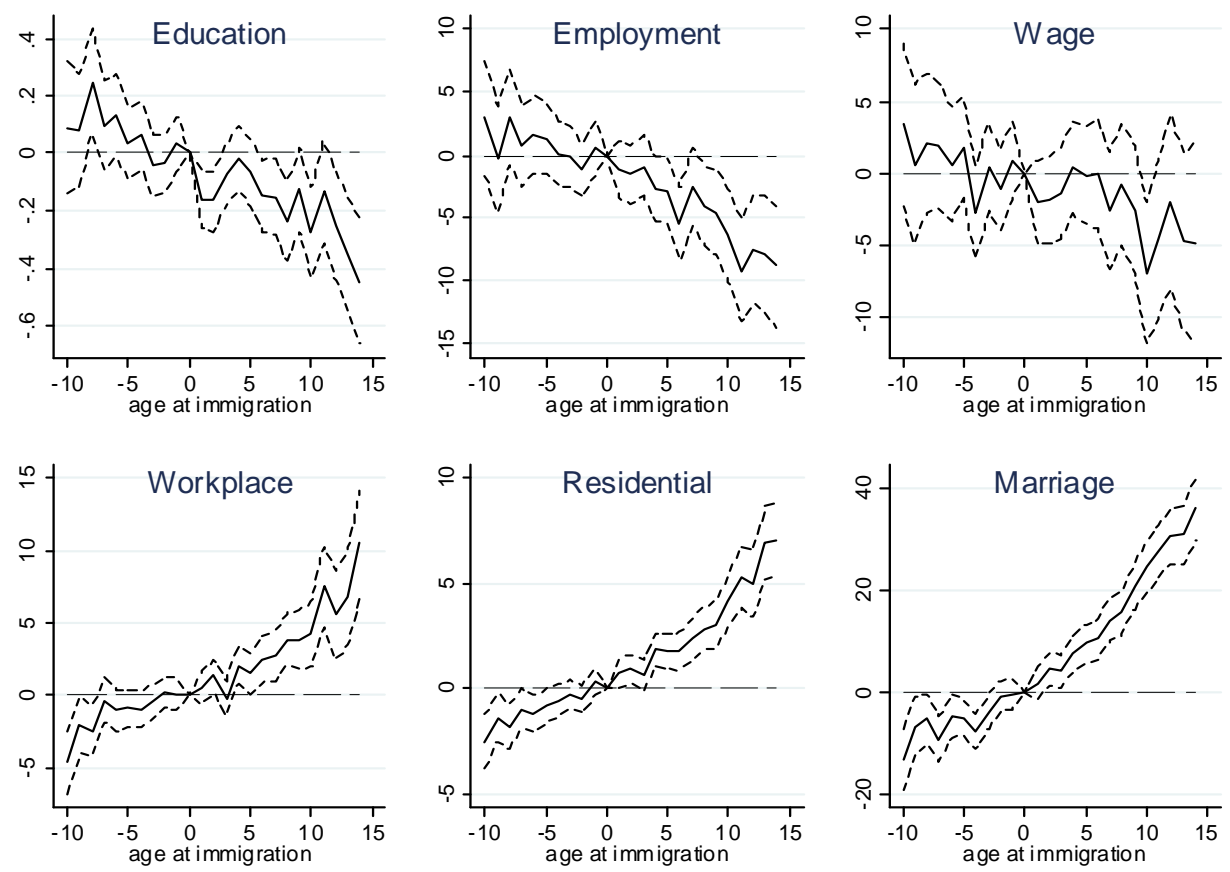

Figure C1 The relationship between age at migration and outcomes - semiparametric estimates

Notes: Estimates and 95\% confidence intervals from family fixed effects specifications described in section 2.3. The employment probability and workplace, residential and marriage exposure are measured at the scale 0 to 100 . Education is years of schooling. Wage is 100 times $\log$ (monthly wage).

Table C2 The impact of one year higher age at migration.

\begin{tabular}{lccc}
\hline & EDU & EMP & WAGE \\
\hline AM $(0,14)$ & $-.019^{* *}$ & $-0.593^{* *}$ & -.003 \\
& $(.006)$ & $(0.135)$ & $(.002)$ \\
AM $(-10,0)$ & $-.021^{* *}$ & -0.214 & -.002 \\
& $(.007)$ & $(0.155)$ & $(.002)$ \\
\hline Observations & 47,625 & 47,890 & 36,753 \\
R-squared & .64 & .52 & .57 \\
Same slope (p-val) & .840 & .045 & .897 \\
Family fixed effects & 19,997 & 20,096 & 15,891 \\
Df & 27,624 & 27,790 & 20,858 \\
Mean Dep Var & 11.52 & 69 & 9.50 \\
\hline
\end{tabular}

Notes: Estimates from sibling regressions including family fixed effects. AM $(-10,0)$ and AM $(0,14)$ indicate the coefficients on age at migration in the respective intervals. "EDU" is years of schooling; "EMP" is employment; "WAGE” is $\log ($ monthly wage). * (**) Statistically significant at the 5(1) percent level. 
Table C3 Socioeconomic outcomes, heterogeneous effects: gender

\begin{tabular}{lccc}
\hline & EDU & EMP & WAGE \\
\hline Men AM (0,14) & $-.015^{*}$ & $-.705^{* *}$ & $-.009 * *$ \\
Men AM (-10,0) & $(.006)$ & $(.147)$ & $(.002)$ \\
& $-.016+$ & $-.366^{*}$ & -.002 \\
Women AM (0,14) & $(.008)$ & $(.178)$ & $(.002)$ \\
& & & \\
Women AM (-10,0) & $-.023^{* *}$ & $-.472 * *$ & $.004 *$ \\
& $(.006)$ & $(.150)$ & $(.002)$ \\
Observations & $-.025 * *$ & -.046 & -.003 \\
R-squared & $(.009)$ & $(.189)$ & $(.002)$ \\
P(same slope for men) & 47,625 & 47,890 & 36,753 \\
P(same slope for women) & .64 & .52 & .58 \\
P(same slope for women and men in AM (0,14) interval) & .108 & .139 & .022 \\
P(same slope for women and men in AM (-10,0) interval) & .332 & .078 & .029 \\
Family fixed effects & 19,997 & 20,096 & 15,891 \\
Df & 27,622 & 27,788 & 20,856 \\
Mean Dep Var, Men & 11.43 & 73 & 9.65 \\
Mean Dep Var, Women & 11.61 & 65 & 9.33 \\
\hline Notes: Estimates from & .861 & .105 & .725 \\
\hline
\end{tabular}

Notes: Estimates from sibling regressions including family fixed effects; see 2.3 for further description. AM $(-10,0)$ and $\operatorname{AM}(0,14)$ indicate the coefficients on age at migration in the respective intervals. "EDU" is imputed years of schooling; "EMP" is employment; "WAGE" is log(monthly wage). The employment probability is measured at the scale 0 to $100{ }^{*}{ }^{* *}$ ) Statistically significant at the 5(1) percent level. 
Table C4 Alternative identification strategy, linear OLS estimates,

\begin{tabular}{|c|c|c|c|c|c|c|}
\hline & EDU & EMP & WAGE & WORK & RESID & MARR \\
\hline & \multicolumn{6}{|c|}{ Sibling sample } \\
\hline \multirow[t]{2}{*}{$\operatorname{AM}(0,14)$} & $-.035 * *$ & $-.474 * *$ & $-.004 * *$ & $.515^{* *}$ & $.440 * *$ & $1.801^{* *}$ \\
\hline & $(.003)$ & $(.063)$ & $(.001)$ & $(.038)$ & $(.024)$ & $(.088)$ \\
\hline \multirow[t]{2}{*}{$\mathrm{AM}(-10,0)$} & $-.047 * *$ & $-.382 * *$ & $-.006 * *$ & $.078 *$ & .022 & $.322 * *$ \\
\hline & $(.004)$ & $(.085)$ & $(.001)$ & $(.039)$ & $(.027)$ & $(.111)$ \\
\hline Observations & 47,625 & 47,890 & 36,753 & 32,696 & 47,890 & 29,685 \\
\hline R-squared & .12 & .05 & .22 & .12 & .19 & .27 \\
\hline P(same slope) & .060 & .570 & .386 & .000 & .000 & .000 \\
\hline Df & 47,379 & 47,644 & 36,508 & 32,452 & 47,644 & 29,437 \\
\hline \multirow[t]{2}{*}{ Mean dep var } & 11.518 & 69.3 & 9.498 & 16.118 & 19.489 & 30.561 \\
\hline & \multicolumn{6}{|c|}{ Full sample } \\
\hline \multirow[t]{2}{*}{$\mathrm{AM}(0,14)$} & $-.033 * *$ & $-.481 * *$ & $-.005 * *$ & $.510^{* *}$ & $.418^{* *}$ & $1.870 * *$ \\
\hline & $(.002)$ & $(.047)$ & $(.001)$ & $(.027)$ & $(.018)$ & $(.062)$ \\
\hline \multirow[t]{2}{*}{$\mathrm{AM}(-10,0)$} & $-.045 * *$ & $-.302 * *$ & $-.004 * *$ & .040 & .036 & $.259 * *$ \\
\hline & $(.003)$ & $(.066)$ & $(.001)$ & $(.029)$ & $(.020)$ & $(.078)$ \\
\hline Observations & 74,029 & 74,335 & 62,591 & 58,351 & 74,334 & 54,086 \\
\hline R-squared & .12 & .05 & .22 & .11 & .17 & .23 \\
\hline P(same slope) & .020 & .243 & .207 & .000 & .000 & .000 \\
\hline Df & 73781 & 74087 & 62344 & 58104 & 74086 & 53834 \\
\hline Mean dep var & 11.648 & 69.5 & 9.510 & 16.149 & 19.327 & 29.350 \\
\hline
\end{tabular}

Notes: Cross-sectional estimates (standard errors) from regressions using alternative identification strategy; see the text for discussion. Upper panel uses sibling sample (cf Table 3), lower panel includes all individuals in the 1960-71 birth cohorts immigrating in the age interval $\left.[-10,14] .{ }^{* *}\right)$ Statistically significant at the 5(1) percent level. 


\section{Figures and tables}
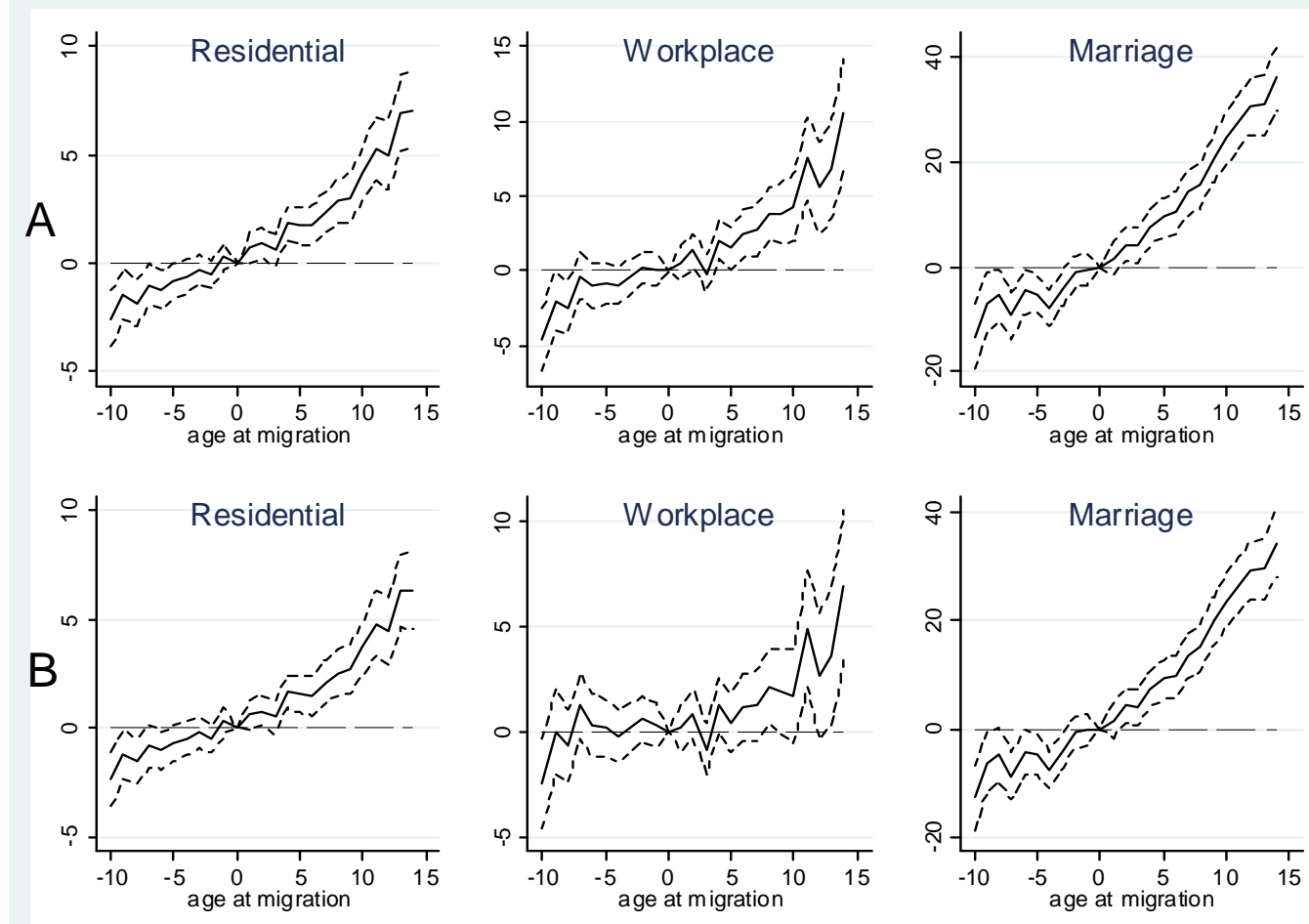

Figure 1 Social segregation and age at migration - semi-parametric estimates.

Notes: Estimates and 95\% confidence intervals from family fixed effects specifications described in section 2. Panel A controls for family fixed effects, gender and birth order.

Panel B controls for family fixed effects, gender, birth order, years of schooling, employment* and wages.

*Employment is not included in panel B when Workplace is the outcome since employment is a condition for inclusion in the workplace regression sample. 

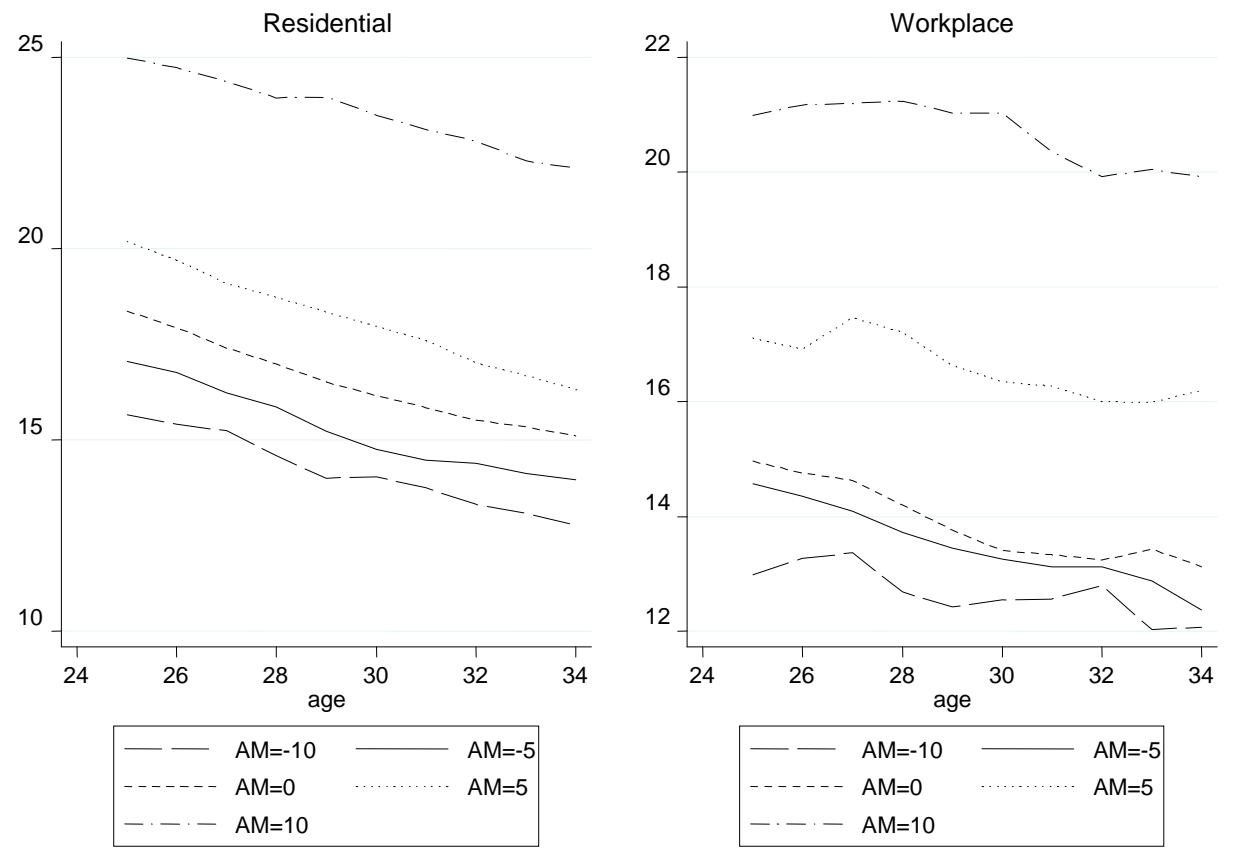

Figure 2 Estimated age profiles, by age at migration.

Notes: The figures plot the estimated age profiles from individual fixed effect estimations for the 25-34 interval for five groups classified according to age at migration (AM). In order to handle observation time effects, the specifications also include controls for the average exposure in the overall sample by calendar year. 
Table 1 Outcomes in different markets and groups (individuals born 1960-1971).

\begin{tabular}{|c|c|c|c|c|}
\hline & & \multicolumn{2}{|c|}{ Used sample } & \multirow[b]{2}{*}{$\begin{array}{r}\text { Immigrated age } \\
15-30\end{array}$} \\
\hline & $\begin{array}{r}\text { Natives with native } \\
\text { parents }\end{array}$ & $\begin{array}{r}\text { Natives with } \\
\text { foreign-born } \\
\text { parents }\end{array}$ & $\begin{array}{r}\text { Immigrated age } \\
0-14\end{array}$ & \\
\hline \multicolumn{5}{|c|}{ Economic outcomes } \\
\hline Education (years) & 12.17 & 11.91 & 11.43 & 11.83 \\
\hline Employment (\%) & 79 & 74 & 66 & 46 \\
\hline Log Wage & 9.56 & 9.58 & 9.45 & 9.35 \\
\hline \multicolumn{5}{|c|}{ Exposure to immigrants (\%): } \\
\hline Workplace & 8 & 14 & 18 & 28 \\
\hline Residential & 12 & 17 & 21 & 29 \\
\hline Marriage & 7 & 18 & 39 & 73 \\
\hline $\mathrm{N}$ & $1,254,026$ & 32,802 & 42,855 & 156,638 \\
\hline
\end{tabular}

Note: Residential exposure is the fraction of neighbors that are foreign-born, workplace exposure is the fraction of co-workers that are foreign-born and Marriage exposure is the fraction of spouses that are foreign-born. For details on definitions, see the data section. Note that those who immigrated after age 15 may have spent substantially shorter time in Sweden at the time of observation.

Table 2 Social segregation and age at migration - linear spline estimates.

\begin{tabular}{lrrrrrr}
\hline & \multicolumn{2}{c}{ RESIDENTIAL } & \multicolumn{2}{c}{ WORKPLACE } & \multicolumn{2}{c}{ MARRIAGE } \\
& \multicolumn{1}{c}{$\mathrm{A}$} & \multicolumn{1}{l}{$\mathrm{B}$} & \multicolumn{1}{l}{$\mathrm{A}$} & \multicolumn{1}{l}{$\mathrm{B}$} & \multicolumn{1}{c}{$\mathrm{A}$} & \multicolumn{1}{c}{$\mathrm{B}$} \\
AM $(0,14)$ & $.416^{* *}$ & $.374^{* *}$ & \multicolumn{1}{c}{$.495^{* *}$} & $.262^{* *}$ & $2.382^{* *}$ & $2.283^{* *}$ \\
& $(.047)$ & $(.046)$ & $(.082)$ & $(.081)$ & $(.175)$ & $(.176)$ \\
AM (-10,0) & $.201^{* *}$ & $.176^{* *}$ & $.235^{* *}$ & .016 & $.961^{* *}$ & $.912^{* *}$ \\
& $(.046)$ & $(.045)$ & $(.076)$ & $(.077)$ & $(.206)$ & $(.206)$ \\
\hline Observations & 47,890 & 47,890 & 32,696 & 32,696 & 29,685 & 29,685 \\
R-squared & .68 & .69 & .59 & .60 & .61 & .61 \\
Same slope (p-val) & .000 & .001 & .011 & .015 & .000 & .000 \\
Family fixed effects & 20,096 & 20,096 & 14,303 & 14,303 & 12,760 & 12,760 \\
Df & 27,790 & 27,786 & 18,389 & 18,385 & 16,921 & 16,917 \\
Mean Dep Var & 19 & 19 & 16 & 16 & 31 & 31 \\
\hline COVARIATES & NO & YES & NO & YES & NO & YES \\
\hline
\end{tabular}

Notes: Estimates from sibling regressions including family fixed effects; see 2.3 for further description. AM $(-10,0)$ and AM $(0,14)$ indicate the coefficients on age at migration in the respective intervals. "RESIDENTIAL", "WORKPLACE" and "MARRIAGE" are immigrant exposure in the workplace, residential and marriage markets, measured at the scale 0 to 100 . All regressions control for gender and birth order. COVARIATES are years of schooling, employment, and wages (among the employed). The outcome and explanatory variables are described and defined in Section 3. * (**) Statistically significant at the 5(1) percent level.

Table 3 Own-group and other-group exposure: spline estimates 


\begin{tabular}{rrrrrrr}
\hline GROUP & own & other & own & other & own & other \\
\hline AM $(0,14)$ & $.135^{* *}$ & $.315^{* *}$ & $.363^{* *}$ & $.140^{*}$ & $2.397^{* *}$ & -.015 \\
& $(.015)$ & $(.041)$ & $(.067)$ & $(.056)$ & $(.167)$ & $(.136)$ \\
AM $(-10,0)$ & $.066^{* *}$ & $.149^{* *}$ & $.185^{* *}$ & .056 & $.962^{* *}$ & -.001 \\
& $(.014)$ & $(.042)$ & $(.055)$ & $(.054)$ & $(.160)$ & $(.152)$ \\
\hline Observations & 47,798 & 47,798 & 32,637 & 32,637 & 29,685 & 29,685 \\
R-squared & .73 & .67 & .58 & .55 & .63 & .52 \\
P(same slope) & .000 & .002 & .024 & .246 & .000 & .942 \\
Fam. fixed eff. & 20,060 & 20,060 & 14,279 & 14,279 & 12,760 & 12,760 \\
Df & 27,734 & 27,734 & 18,354 & 18,354 & 16,921 & 16,921 \\
Mean dep var & 4 & 15 & 6 & 10 & 19 & 12 \\
\hline
\end{tabular}

Notes: Estimates from sibling regressions including family fixed effects; see 2.3 for further description. All regressions include controls for gender and birth order. AM $(-10,0)$ and AM $(0,14)$ indicate the coefficients on age at migration in the respective intervals. "Own-group” are people from the mother's country of birth; "Other-group” are other foreign-born. "RESIDENTIAL”, "WORKPLACE” and "MARRIAGE” are immigrant exposure in the workplace, residential and marriage markets. The workplace, residential and marriage exposure are measured at the scale 0 to 100 . The outcome variables are described and defined in Section 3.* (**) Statistically significant at the 5(1) percent level. 
Table 4 Heterogeneous effects: gender

\begin{tabular}{|c|c|c|c|}
\hline & RESID & WORK & MARR \\
\hline \multirow[t]{2}{*}{ Men AM $(0,14)$} & $.450 * *$ & $.647 * *$ & $2.470 * *$ \\
\hline & $(.051)$ & $(.092)$ & (.193) \\
\hline \multirow[t]{2}{*}{ Men AM $(-10,0)$} & $.197 * *$ & $.238 * *$ & $.604^{*}$ \\
\hline & $(.053)$ & $(.088)$ & $(.243)$ \\
\hline \multirow[t]{2}{*}{ Women AM $(0,14)$} & $.380 * *$ & $.327 * *$ & $2.304^{* *}$ \\
\hline & $(.052)$ & $(.091)$ & $(.190)$ \\
\hline \multirow[t]{2}{*}{ Women AM $(-10,0)$} & $.205^{* *}$ & $.222 *$ & $1.291^{* *}$ \\
\hline & $(.054)$ & $(.091)$ & $(.245)$ \\
\hline Observations & 47,890 & 32,696 & 29,685 \\
\hline R-squared & .68 & .60 & .61 \\
\hline $\mathrm{P}$ (same slope for AM $(0,14)$ and AM $(-10,0)$, Men $)$ & .001 & .001 & .000 \\
\hline $\mathrm{P}$ (same slope for AM $(0,14)$ and AM $(-10,0)$, Women $)$ & .018 & .417 & .001 \\
\hline $\mathrm{P}$ (same slope for women and men, AM $(0,14)$ interval) & .106 & .000 & .291 \\
\hline $\mathrm{P}$ (same slope for women and men, AM $(-10,0)$ interval) & .886 & .871 & .009 \\
\hline Family fixed effects & 20,096 & 14,303 & 12,760 \\
\hline Degrees of freedom & 27,788 & 18,387 & 16,919 \\
\hline Mean dependent variable, Men & 20 & 17 & 26 \\
\hline Mean dependent variable, Women & 19 & 15 & 34 \\
\hline
\end{tabular}

Notes: Estimates from sibling regressions including family fixed effects; see 2.3 for further description. All regressions include controls for gender and birth order. AM $(-10,0)$ and AM $(0,14)$ indicate the coefficients on age at migration in the respective intervals. "RESID", "WORK” and "MARR" are immigrant exposure in the workplace, residential and marriage markets, measured at the scale 0 to 100 . The outcome variables are described and defined in Section 3. * (**) Statistically significant at the 5(1) percent level. 